\title{
IMPLEMENTASI PENDIDIKAN KARAKTER DALAM PEMBELAJARAN IPS SISWA KELAS V SDN KAMPUNG MELAYU 4 KABUPATEN TANGERANG
}

\author{
Hesti Wahyuni ${ }^{1}$, Sa'odah $^{2}$, Septy Nurfadhillah ${ }^{3}$ \\ ${ }^{1,2,3}$ Universitas Muhammadiyah Tangerang, Kota Tangerang \\ 1hestiwahyuni3010@gmail.com \\ ${ }^{2}$ saodah.umt@gmail.com \\ ${ }^{3}$ nurfadhillahsepty@gmail.com
}

\begin{abstract}
ABSTRAK
Fokus penelitian ini adalah Implementasi mata pelajaran IPS terhadap pembentukan karakter peduli lingkungan siswa kelas VA di SDN Kampung Melayu 4 Kabupaten Tangerang. tujuan penelitian ini adalah untuk mendskripsikan karakter peduli lingkungan siswa dalam pembelajaran IPS siswa kelas VA SDN Kampung Melayu 4 Kabupaten Tangerang. Pendekatan penelitian ini adalah pendekatan kualitatif. Jenis metode penelitian yang di pakai adalah jenis metode penelitian analisis deskritif kualitatif. Teknik pengumpulan data pada penelitian ini terdiri dari wawancara, observasi, angket dan dokumentasi. Hasil penelitian pada penelitian ini adalah implementasi pendidikan karakter peduli lingkungan dalam pembelajaran IPS siswa kelas VA sudah diterapkan dengan baik.
\end{abstract}

Kata kunci: Pendidikan karakter, peduli lingkungan, pembelajaran IPS

\section{ABSTRACT}

The focus of this research is the implementation of social studies subjects on the formation of environmental care character for Grade VA students at SDN Kampung Melayu 4, Tangerang Regency. The purpose of this study was to describe the environmental care character of students in social studies learning for Grade VA at SDN Kampung Melayu 4, Tangerang Regency. This research approach is a qualitative approach. The type of research method used is a type of qualitative descriptive analysis research method. Data collection techniques in this study consisted of interviews, observations, questionnaires, and documentation. The result of this research is that the implementation of environmental care character education in social studies learning for grade VA students has been implemented well.

Keywords: Character education, environmental care, social studies learning

\section{PENDAHULUAN}

Pendidikan merupakan hal yang dibutuhkan oleh semua manusia sebagai bekal agar memperoleh keberhasilan dan meraih kesuksesan dalam kelanjutan hidupnya. Dengan pendidikan, seseorang dapat mengembangkan potensi yag ada pada dirinya dan membentuk yang lebih baik agar dapat bermanfaat bagi masyarakat dan lingkungan.

Pendidikan merupakan usaha sadar dan terencana untuk mewujudkan suasana belajar dan proses pembelajaran agar peserta didik secara aktif mengembangkan potensi dirinya untuk memiliki kekuatan spiritual keagamaan, pengendalian diri, kecerdasan, akhlak mulia, serta keterampilan yang diperlukan dirinya, masyarakat, bangsa, dan negara.

Pendidikan di Indonesia adalah seluruh pendidikan yang diselenggarakan di Indonesia, pendidikan di Indonesia menjadi tanggung jawab Kementrian Pendidikan dan Kebudayaan (Kemendikbud). Semua pendidikan di Indonesia wajib mengikuti program pendidikan wajib belajar pendidikan dasar selama 12 Tahun, enam tahun di sekolah 
dasar atau madrasah ibditaiyah, kemudian tiga tahun di sekolah menengah pertama atau madrasah tsanawiyah, dan 3 tahun di sekolah menengah atas atau madrasah Aliyah.

Pendidikan di Indonesia diatur melalui Undang-Undang No. 20 Tahun 2003 Pasal 3 yang menyebutkan bahwa: Pendidikan Nasional berfungsi mengembangkan kemampuan dan membentuk watak serta peradaban bangsa yang bermartabat dalam rangka mencerdaskan kehidupan bangsa, bertujuan untuk berkembangnya potensi siswa agar menjadi manusia yang beriman dan bertaqwa kepada Tuhan Yang Maha Esa, berakhlak mulia, sehat, berilmu, cakap, kreatif, mandiri, dan menjadi warga Negara yang demokratis serta bertanggung jawab.

Sekolah sebagai lembaga Pendidikan berkewajiban memberikan kesempatan belajar seluas-luasnya kepada siswa untuk mengembangkan dirinya semaksimal mungkin sesuai dengan potensi yang dimilikinya. Sekolah dirancang untuk berlangsungnya proses belajar mengajar antara siswa dengan guru beserta warga sekolah. Guru merupakan seseorang yang berperan dalam menciptakan sumber daya manusia yang berkualitas. Guru memegang peran penting bagi keberhasilan dalam proses pembelajaran. Seorang guru dalam proses pembelajaran harus mampu menciptakan suasana kelas yang inovatif, kreatif, dan menyenangkan sehingga siswa menyukai belajar dan bisa mencapai hasil yang diinginkan. Jenjang sekolah dasar merupakan suatu pondasi awal yang mendasari terciptanya sumber daya manusia yang berkualitas.

Salah satu mata pelajaran yang ada dalam kurikulum pendidikan Sekolah Dasar ialah Ilmu Pengetahuan sosial (IPS). Pendidikan IPS merupakan gabungan ilmuilmu sosial yang terintegrasi atau terpadu.
Pengertian terpadu, bahwa bahan atau materi IPS diambil dari ilmu-ilmusosial yang di padukan dan tidak terpisah-pisah. Pengajaran IPS (Socil studies), sangat penting bagi jenjang Pendidikan dasar dan menengah karena siswa yang datang kesekolah berasal dari lingkungan yang berbeda-beda. Pengenalan mereka tentang masyarakat, tempat mereka menjadi anggota di warnai oleh lingkungan mereka tersebut. Sekolah bukanlah satu-satunya wahana atau sarana untuk mengenal masyarakat.

Pengetahuan konsep, teori-teori IPS yang diperolah anak di dalam kelas dapat dicocokan dan dicobakan sekaligus diterapkan dalam kehidupan sehari-hari di masyarakat. Pembelajaran IPS diarahkan atau bertujuan untuk membina anak didik menjadi warga negara yang baik, yang memiliki pengetahuan, keterampilan, dan keperdulian terhadap lingkungan yang berguna bagi dirinya serta bagi masyarakat dan negara.

Peduli lingkungan adalah sikap dan Tindakan yang selalu berupaya mencegah kerusakan pada lingkungan alam di sekitarnya dan mengembangkan upaya-upaya untuk memperbaiki, kerusakan alam yang sudah terjadi. Melaluai Pendidikan karakter diharapkan dapat mampu membantu membangkitkan dan mewujudkan kepedulian lingkungan. Caranya ialah dengan mengenalkan anak-anak tentang pentingnya menjaga lingkungan. Dengan tujuan menumbuhkan rasa cinta anak terhadap lingkungannya, untuk menumbuhkan rasa cinta lingkungan anak sehingga menjadikan manusia yang berguna bagi masyarakat dan lingkungannya.

Pembelajaran dapat dilakukan dengan mengajarkan anak untuk membuang sampah pada tempatnya, menyayangi tumbuhtumbuhan, dan dan selalu menjaga kebersihan di tempat mana pun berada. Dalam hal teori 
siswa dibekali dan disisipi materi yang berkaitan dengan lingkungan. Siswa juga diberi tugas yang ada kaitannya dengan lingkungan. Dalam hal praktek siswa diberi kegiatan tentang kecintaan dan peduli pada lingkungan, meskipun sekedar kebersihan kelas. Jadi sebelum memulai pembelajaran guru mengevaluasi kebersihan kelas. Pada saat pembelajaran siswa selalu dikait-kaitkan dan diingatkan untuk peduli lingkungan istilah karakter lebih fokus pada tindakan atau tingkah laku. karakter adalah watak yang tercermin dalam tindakan atau tingkah laku sebagai manifestasi dari sifat-sifat jiwa manusia (pikiran, perasaan, dan kehendak) sekaligus penanda kepribadian seseorang yang khas, termasuk kaitannya dalam menyesuaikan diri dengan lingkungan.

Berdasarkan hasil observasi dan wawancara pada wali kelas $\mathrm{V}$ pada tanggal 1 maret 2021, di SD Negeri Kampung Melayu 4 Kabupaten Tangerang, ditemukan fakta bahwa dalam penerapan karakter khususnya karakter peduli lingkungan masih banyak permasalahan yang terjadi seperti siswa yang sering buang sampah sembarangan, dikarenakan masih kurangnya kepedulian siswa terhadap lingkungan sekolah, mengotori lingkungan sekolah, tidak mau di ajak membersihkan lingkungan walaupun guru sudah menerapkan nilai-nilai peduli lingkungan dalam pembelajaran tesebut dengan baik.

Karakter peduli lingkungan perlu di bangun dalam diri anak. Karakter ini meliputi peduli lingkungan sosial dan lingkungn alam. Karakter peduli lingkungn sosial merupakan sebuah sikap dan tindakan yang menunjukan upaya untuk memberikan bantuan baik moril maupun materil bagi orang lain yang membutuhkan. Sikap ini menujukan kepekaan terhadap kondisi sekitar. Karakter peduli lingkungan alam merupakan sikap yang ditunjukan dengan perbuatan menjaga lingkungan alam sekitarnya. sikap ini juga ditunjukan dengan tindakan memperbaiki kerusakan lingkungan yang terjadi. Karakter ini membuat kelangsungan alam terjaga. Kedua karakter ini perlu dibangun dalam diri anak-anak supaya dapat memiliki sikap yang peka terhadap lingkungan baik sosial dan alam.

Berdasarkan pemaparan latar belakang diatas, maka penulis tertarik mengambil judul "Implementasi Pendidikan karakter dalam pembealajarn IPS Siswa Kelas V SDN Kampung Melayu 4 Kabupaten Tangerang".

\section{METODE PENELITIAN}

Pendekatan yang digunakan pada penelitian ini menggunakan pendekatan kualitatif. Menurut Sugiyono (2019) pendekatan kualitatif di gunakan untuk meneliti pada kondisi obyek yang alamiah, di mana peneliti adalah sebagian instrument kunci, teknik pengumpulan data dilakukan secara trianggulasi (gabungan observasi, wawancara, dokumentasi), data yang diperoleh cenderung data kualitatif (h.25).

Menurut Lofland dan Lofland dalam Maleong (2014, h, 157), sumber data utama dalam penelitian kualitatif ialah kata-kata, dan tindakan, selebihnya adalah data tambahan seperti dokumen dan lain-lain. Sumber data dalam penelitian ini yaitu berupa audiovisual berupa rekaman dan isi lampiran dari rekaman tersebut di sekolah SDN Kampung Melayu 4 Kabupaten Tangerang. Adapun jenis data penelitiannya terdiri dari: data primer dan data sekunder. Untuk mengumpulkan data yang dapat mendukung fokus masalah dalam penelitian ini, teknik pengumpulan data yang dilakukan yaitu dengan: wawancara, observasi, angket dan studi dokumentasi. 
Teknik analisis data, merupakan proses penyusunan data secara sistematis yang terdapat dalam sumber data yang di gunakan oleh peneliti. Menurut Sugiyono (2019, h. 435) berpendapat bahwa analisis data adalah proses mencari dan menyusun secara sistematis data yang diperoleh dari hasil wawancara, catatan lapangan, dan bahan-bahan lain, sehingga dapat mudah difahami, dan temuannya dapat diinformasikan kepada orang lain. Analisis data dilakukan dengan mengorganisasikan data, menjabarkannya ke dalam pola, memilih mana yang penting dan yang akan dipelajari, dan membuat kesimpulan yang dapat diceritakan kepada orang lain. Teknik analisis data pada penelitian ini mengenai tentang analisis pembentukan karakter siswa kelas V SDN Kampung Melayu 4 Kabupaten Tangerang. Model yang digunakan dalam analisis kualitatif ini adalah model Miles dan Huberman (1984) yaitu reduksi data, penyajian data dan penarikan kesimpulan. Untuk mendapatkan data yang akurat maka harus dilakukan pemeriksaan sumber data. Dalam penelitian ini menggunakan trianggulasi. Menurut Sugiyono (2019) "Tringgulasi dalam pengujian kredibilitas ini diartikan sebagai pengecekan data dari berbagai sumber dengan berbagai cara, dan berbagai waktu.

\section{HASIL DAN PEMBAHASAN}

Implementasi pendidikan karakter dalam ilmu pengetahuan sosial di SDN Kampung Melayu 4 sudah diterapkan, Pendidikan karakter pada siswa sangat penting dalam pembentukan karakter anak di sekolah dasar, untuk membentuk pribadi yang baik, bijaksana, jujur, bertanggung jawab dan bisa menghormati orang lain. Terkhusus kepada karakter peduli lingkungan dimana anak pada usia sekolah dasar perlu di tanamkan nilai karakter peduli lingkungan dengan cara pembiasaan-pembiasaan yang di lakukan seperti melakukan rutinitas membersihkan ruangan kelas, yang sudah sesuai dengan jadwal piketnya, siswa yang bertugas piket membersihkan lingkungan kelas sekitar, pembiasaan siswa membawa tempat makan dari rumah untuk menghindari pemakaian plastik ketika jajan, membuang sampah pada tempanya.

Pendidikan karakter peduli lingkungan memang sudah seharunya diajarkan kepada peserta didik sejak dini atau pada usia sekolah dasar. Karena dengan ditanamkannya nilai pendidikan karakter peduli lingkungan di usia sekolah dasar peserta didik akan menjadi terbiasa dan peduli terhadap lingkungan. Dimana menurut Syukri Hamzah (2013) menyatakan bahwa karakter peduli lingkungan bukanlah sepenuhnya talenta maupun instink bawan, akan tetapi juga merupakan hasil dari suatu proses pendidikan dalam arti luas. (Amirul Mukminin, 2014, h. 299).

Berdasarkan dari hasil wawancara, yang dilakukan oleh peneliti, kepada kepala sekolah, guru dan siswa kelas VA, Implementasi pendidikan karakter pada mata pelajaran IPS sudah diterapkan di SDN Kampung Melayu 4 Kabupaten Tangerang. Hal ini di perkuat dengan pernyataanpernyataan dari kepala sekolah yang menjelaskan beberapa tanggapannya dari pertanyaan yang diberikan oleh peneliti seperti, tujuan dari menerapkan nilai-nilai karakter disekolah adalah dengan harapan siswa dan siswinya bisa menjadi siswa dan siswi yang cerdas, memiliki tanggung jawab dan karakter yang baik, kepala sekolah juga menjelaskan bahwa penanaman nilai karakter pada siswa sangat penting dalam pembentukan karakter siswa di usia sekolah 
dasar, dengan menanamkan kebiasaankebiasaan yang baik agar siswa selalu ingat, karena anak bisa karena terbiasa kebiasaan itu yang akan tertanam dan menjadi karakter siswa, dimana masa usia pendidikan sekolah dasar dibutuhkan penanaman nilai karakter, karena penting untuk membentuk keperibadian anak.

$$
\text { Selanjutnya kepala sekolah }
$$
mengatakan ada beberapa kegiatan yang ada di SDN Kampung Melayu 4 yang mendukung pembentukan karakter salah satunya yaitu seperti melakukan tadarus bersama setiap Jumat pembentukan karakter religius, melakukan upacara bendera yang di lakukan setiap hari senin merupakan pembentukan karakter cinta tanah air, jum'at bersih yang biasanya dilakukan oleh seluruh warga sekolah melakukan bersih-bersih termasuk pembentukan karakter peduli lingkungan dan kegiatan yang di adakan satu tahun sekali yaitu lomba kebersihan kelas yang bertujuan untuk melatih siswa lebih perduli lagi dengan lingkungan sekitar dengan menjaga lingkungan kelas yg bersih dan rapih. Dan terdapat kegiatan kreativitas dan inovasi warga sekolah dalam upaya pengelolaan lingkungan hidup seperti daur ulang sampah dan pemanfaatan barang-barang bekas biasanya, membuat pot bunga dari barang bekas seperti botol aqua yang sudah kosong, lalu di beri warna sehingga menarik. Diperkuat dari hasil angket bahwa implementasi pendidikan karakter peduli lingkungan sudah di terapkan di SDN Kampung Melayu 4 Kabupaten Terlihat dari hasil angket yang di jawab oleh siswa kelas Va.

\section{KESIMPULAN DAN SARAN}

\section{Kesimpulan}

Berdasarkan hasil penelitian dan pembahasan sebagaimana yang telah penulis uraikan pada bab sebelumnya, maka peneliti dapat menarik kesimpulan bahwa Implementasi pendidikan karakter dalam pembelajaran IPS siswa kelas V Tema 4 Subtema 1 pembelajaran 3 SDN Kampung Melayu 4 Kabupaten Tangerang telah mengimplementasikan nilai karakter peduli lingkungan di sekolah dengan baik. melalui dari pembiasan-pembiasaan yang dilakukan disekolah seperti dalam memelihara lingkungan kelas biasanya membagi tugas piket setiap harinya bergantian membersihkan kelas secara bersama-sama sesuai dengan jadwalnya, juga mengadakan denda jika ada sampah di lingkungn kelas dengan tujuan anak bisa selalu menjaga lingkungan kelasnya.

Dengan pelaksanaan pendidikan kaerakter perduli lingkungan melalui penanaman nilai-nilai karakter disekolah, yaitu melalui penyediaan fasilitas-fasilitas, sarana dan prasarana yang memadai untuk mendukung berbagai aktivitas pada program sekolah maupun yang dibiasakan dalam kehidupan sehari-hari disekolah. Program atau kegiatan tersebut bertujuan untuk membentuk karakter siswa melalui aktivitasaktivitas dilingkungan sekolah. Yang di bentuk sedemikian rupa sehingga siswa baik secara sadar maupun tidak sadar telah membiasakan diri dengan nilai-nilai karakter yang direncanakan sekolah.

\section{Saran}

Berdasarkan dalam kesimpulan penelitian implementasi pendidikan karakter peduli lingkungan di SDN Kampung Melayu 4 Kabupaten Tangerang, terdapat saran sebagai berikut:

\section{Untuk Kepala Sekolah}

Kepala sekolah harus lebih banyak membuat kegiatan kegiatan yang menyangkut pengimplementasian pendidikan karakter 
disekolah, dan memfasilitasi lebik banyak lagi sarana dan prasarana yang memadai untuk mendukung berbagai kegiaatan sekolah maupun yang dibiasakan dalam kehidupan sehari-hari di sekolah.

\section{Untuk Guru}

Guru harus selalu mencontohkan yang baik ke peserta didik, karena guru sebagai model untuk siswa dimana peserta didik akan mencotoh apa yang dilakukan gurunya, dan sesekali mengganti metode belajar dengan metode yang lain agar anak tidak bosan dengan metode ceramah

\section{DAFTAR PUSTAKA}

Ali, A. M. (2018). Pendidikan Karakter: Konsep dan Implementasinya. Jakarta: Renada Media Group.

Arifin, B. S., \& Rusdiana, H. A. (2019). Manajemen Pendidikan Karakter. Bandung: Pustaka Setia.

Arikunto, S. (2013). Manajemen Penelitian. Jakarta: Rineka Cipta.

Amirul Mukminin Al-Anwari. (2014). Strategi Pembentukan Karakter Peduli Lingkungan Di Sekolah Adiwiyata Mandiri

Dirman, \& Juarsih, C. (2014). KARAKTERISTIK PESERTA DIDIK (Dalam Rangka Implementasi Standar Proses Pendidikan Siswa. Jakarta: Renaka Cipta.

Gunawan, H. (2017). Pendidikan Karakter : Konsep dan Implementasi. Bandung: Alfabeta.

Gunawan, H. (2017). Pendidikan Karakter : Konsep dan Implementasi. Bandung: Alfabet.

Hamid, H., \& Saebani, B. A. (2013). Pendidikan Karakter Islam. Bandung: Pustaka Setia.
Huda, M. (2017). Model-Model Pengajaran dan Pembelajaran. Yogyakarta: Pustaka Pelajar.

Huda, N. . (2021). Implementasi Pendidikan Karakter Selama Learning From Home Di Sekolah Dasar. Berajah Journal, 1(3), 111-116.

https://doi.org/10.47353/bj.v1i3.29

Moleong, L. J. (2017). Metodelogi Penelitian Kualitatif. Bandung: Rosda.

Muslich, M. (2018). Pendidikan Karakter Menjawab Tantangan Krisis Multidimensional. Jakarta: Bumi Aksara. Nara, H., \& Siregar, E. (2019). Teori Belajar dan Pembelajaran. Bogor: Ghalia Indonesia.

Rachman, H. (2014). Pengembangan Profesi Pendidikan IPS. Bandung: Alfabet.

R, R. (2021). Hubungan Konsentrasi Belajar Siswa Terhadap Prestasi Belajar Peserta Didik Pada Masa Pandemi Covid-19 Di SDN Karang Mekar 4 Banjarmasin. Berajah Journal, 1(2), 72-75. https://doi.org/10.47353/bj.v1i2.8

Salahudin, A., \& Alkrienciechie, I. (2017). Pendidikan Karakter : Pendidikan Berbasis Agama \& Budaya Bangsa. Bandung: Pustaka Setia.

Samani, M., \& Hariyanto. (2017). Konsep dan Model Pendidikan Karakter. Bandung: Rosda.

Sardjoyo, dkk. (2014). Pendidikan IPS di SD. Tangerang Selatan: Universitas Terbuka. Sayudi. (2012). Strategi Pembelajaran Pendidikan karakter. Yogyakarta: Rosda. Siska, Y. (2016). Konsep Dasar IPS. Yogyakarta: Garudhawaca.

Sugiyono. (2019). Metode Penelitian Pendidikan. Bandung: Alfabet.

Suprijono, A. (2017). Cooperative Learning : Teori \& Aplikasi Paikem. Yogyakarta: Pustaka Pelajar. 
ISSN 2797-1805

Wahab, A. A., \& dkk. (2015). Konsep Dasar IPS. Tangerang Selatan: Universitas Terbuka. 